\title{
An in-vitro assessment of micro-shear bond strength of a nano adhesive to dentin with different types of composite restorative systems
}

\begin{abstract}
Objective: The present study evaluated the micro-shear bond strength of a nano adhesive to dentin with different types of composite restorative systems.

Materials and method: Thirty caries-free, freshly extracted human molar teeth were sliced to expose dentin. The dentin slices were randomly divided into three main groups (10 each) and bonding was done at three sites so as to create total 90 samples with 30 in each group. Group A: nanofilled Composite, Group B: Tetric EvoCeram Bulk fill and Group C: Sonic Fill Bulk fills composite. Adhesive (nano bond) was used for bonding in all the groups. After 24 hours of immersion in water at $37^{\circ} \mathrm{C}$, then subjected to thermocycling, a microshear bond test was carried out. One way analysis of variance (ANOVA) and Tukey's tests were used for testing the significance between the means of tested groups ( $\mathrm{P}$ value $\leq 0.05$ ).
\end{abstract}

Result: The mean micro-shear bond strength values for Groups A, B, C were 10.4, 13.85 and 17.16 MPa respectively.

Conclusion: Sonic Fill Bulk fills composite and nano bond displayed the highest microshear bond strength to dentin.

Keywords: adhesive, bulk fill, bond strength, composite, dentin, micro-shear, nano
Volume 5 Issue 2 - 2016

\author{
Ammar S Al Shamrani \\ Department of Restorative Dental Sciences, Faculty of \\ Dentistry, Taif University, Saudi Arabia
}

\section{Correspondence: Ammar S Al Shamrani, Department of Restorative Dental Sciences, Faculty of Dentistry, Taif University, Saudi Arabia, Tel +966554419274,}

Email Drammare@tudent.edu.sa

Received: September 23, 2015 | Published: September 30

\section{Introduction}

Nearly half of all dental restorations fail within 10 years and replacing this account for $50-70 \%$ of all restorative dentistry. ${ }^{1}$ Composites are popular restorative materials because of their esthetics and direct-filling capabilities..$^{2-8}$ One main problem, however, is that composite tend to accumulate more biofilm than other restorative materials in vivo. ${ }^{9-11}$ Biofilms at the restoration margins could produce acids and cause secondary caries, one of the main reasons for restoration failure. ${ }^{12,13}$ In addition to this, the polymerizations of resin based composites generate stresses due to their contraction. Shrinkage stress occurs when the contraction is obstructed and the material is rigid enough to resist sufficient plastic flow to compensate for the original volume. The magnitude of contraction stresses is highly dependent on the visco-elastic properties of the material. ${ }^{14}$ Clinically, these stresses may be transferred to the margins of the restoration, possibly affecting marginal quality. ${ }^{15}$ When marginal quality is not adequate, problems like leakage, recurrent caries and pulpal irritation may occur. ${ }^{16,17}$ Even by considering that an absolutely perfect marginal seal is not achievable clinically, a good marginal seal should be the main objective for clinicians. Restorative materials and placement techniques are widely recognized as a major factor in the modification of shrinkage stresses. ${ }^{18}$ The introduction of nano composites has significantly reduced the micro leakage and improved the overall marginal quality. Nano composites can be roughly classified into two categories: one is intercalated nano composites and the other is exfoliated. An intercalated nano composite, in which the silicate is well-dispersed in a polymer matrix with polymer chains inserted into silicate layers that retain their lateral order, and exfoliated nanocomposites where the silicate platelets become fully separated or delaminated, essentially individually dispersed in the polymer matrix. ${ }^{19}$ Recently introduced Bulk Fill composites also possess specific characteristics, including enhanced flowability to achieve consistent adaptation to the cavity preparation. Elasticity and low polymerization shrinkage stress reduce micro leakage, postoperative sensitivity, and secondary caries. Improved depth of cure of at least 4 $\mathrm{mm}$ eliminates the need for layering. ${ }^{20}$ The recent introduction of the Sonic Fill (Kerr corp, USA) combines the attributes of a low viscosity composite and a universal composite. By activating the composite with sonic energy, it is possible to fill the cavity and adapt the low viscosity material easily and then compact and model it while the composite changes its consistency until it reaches a higher viscosity. As per the manufacturer, the advantages are reduced working time and polymerization shrinkage, better adaptation to cavity walls and ease of use..$^{21}$ The purpose of this study was to evaluate micro-shear bond strength of a nanofilled Composite, Tetric EvoCeram Bulk fill and Sonic Fill Bulk fill composites bonded with a nano reinforced adhesive nano bond.

\section{Materials and methods}

Three different types of composite restorative material were used in this study: Nanofilled composite (Artiste Nanocomposite, Pentron 
Clinical Technologies LLC, USA, lot \#182066-185215), Tetric EvoCeram Bulk fill (Ivoclar vivadent AG, Schaan, Liechtenstien, lot \#P48872) and Sonic Fill Bulk fill composite (Kerr, Orange, CA, USA, lot \#3691651). Nano-bond adhesive (Pentron Syborn Clinical Technologies, USA, lot \#183421) was used for bonding all specimens in this study. Thirty caries-free freshly extracted human molar teeth were collected for use in this study. The teeth were cleaned by ultrasonic scaler and stored in distilled water at $37^{\circ} \mathrm{C}$ before testing. A dentin slice, approximately $1.0 \mathrm{~mm}$ thick, was cut perpendicular to the long axis of each tooth from the upper-middle coronal portion region using a low-speed diamond saw (IsoMet ${ }^{\circledR}$, Buehler, Lake Bluff, IL) under water coolant. The occlusal surfaces of slices were ground with silicon carbide paper up to \#600 grit to expose a flat dentin surface. ${ }^{22-25}$ The dentin slices were randomly divided into three main groups (containing 10 each) according to the type of composite resins used.
a. Group A: nanofilled Composite (control group)
b. Group B: Tetric EvoCeram Bulk fill and
c. Group C: Sonic Fill Bulk fills composite

Each dentin slice was acid etched using $37 \%$ phosphoric acid gel (Eco-Etch. Ivoclar Vivadent) for 15 seconds then the dentin slices were rinsed with water sprays and bloated for five seconds. The adhesives were applied on the dentin surfaces by the appropriate manufacturer's instructions. The adhesives were applied to the entire dentin surface and air thinned for 15 seconds. A gentle stream of dry air was applied to disperse the material into a thin, uniform, shiny surface and prior to curing, three cylinders (internal diameter: $0.7 \mathrm{~mm}$, height: $1.0 \mathrm{~mm}$ ) of Tygon ${ }^{\circledR}$ microbore tubing (R-3603, Norton Performance Plastic CO, Cleveland, $\mathrm{OH})$ were placed on the flat dentin at different locations. The adhesive was then light-cured for 10 seconds with LED curing light.
After curing, each tube was filled with composite resin and then light-cured for 40 seconds with the tip as close to the surface as possible. Curing radiometer equipment was used to ensure steady light intensity throughout the polymerization of all specimens. All restorations were finished and polished with a set of soflex discs (3M Company, St. Paul MN, USA). The specimens were stored in moist conditions at a room temperature of $23^{\circ} \mathrm{C}$ for one hour prior to removing the Tygon tubing. So, a total of 30 discs with 90 samples and 30 for each group were obtained. The specimens were immersed in water at $37^{\circ} \mathrm{C}$ for 24 hours then subjected to thermocycling to simulate clinical thermal stress conditions before testing, according to the ANSI/ADA specifications [26] and the International Organization for Standardization (ISO) $)^{27}$ for direct filling resins and dental adhesives. All specimens were subjected tothermocycling by alternatively storing in water reservoirs at $5^{\circ} \mathrm{C}$ and $55^{\circ} \mathrm{C}$, respectively, with a dwell time of 30 seconds and transfer time of 15 seconds. This procedure was carried out for 500 cycles and was controlled by a computer to simulate thermal stress ${ }^{28}$ the resin cylinders were then subjected to the micro-shear bond test 24 (Figure $1 \&$ 2). Each dentin slice with the resin cylinders was placed in the lower attachment of the universal testing machine (LRXPlus II, Lloyd Instruments Ltd, Fareham, UK) for micro-shear bond testing. A thin wire (diameter $0.20 \mathrm{~mm}$ ) was looped around each resin cylinder, making contact through half of the cylinder base and was placed as close as possible to the resin-dentin interface. A shear force was applied to each specimen at a crosshead speed of $0.5 \mathrm{~mm} / \mathrm{min}$ until failure occurred. The resin-dentin interface of the specimens and the wire loop were aligned as straight as possible to ensure that the same orientation in shear was maintained. The loads at failure were recorded and the data was analyzed by one way ANOVA. Tukey's post-hoc test was used for pair wise comparisons between the means when the ANOVA test was significant.
Load

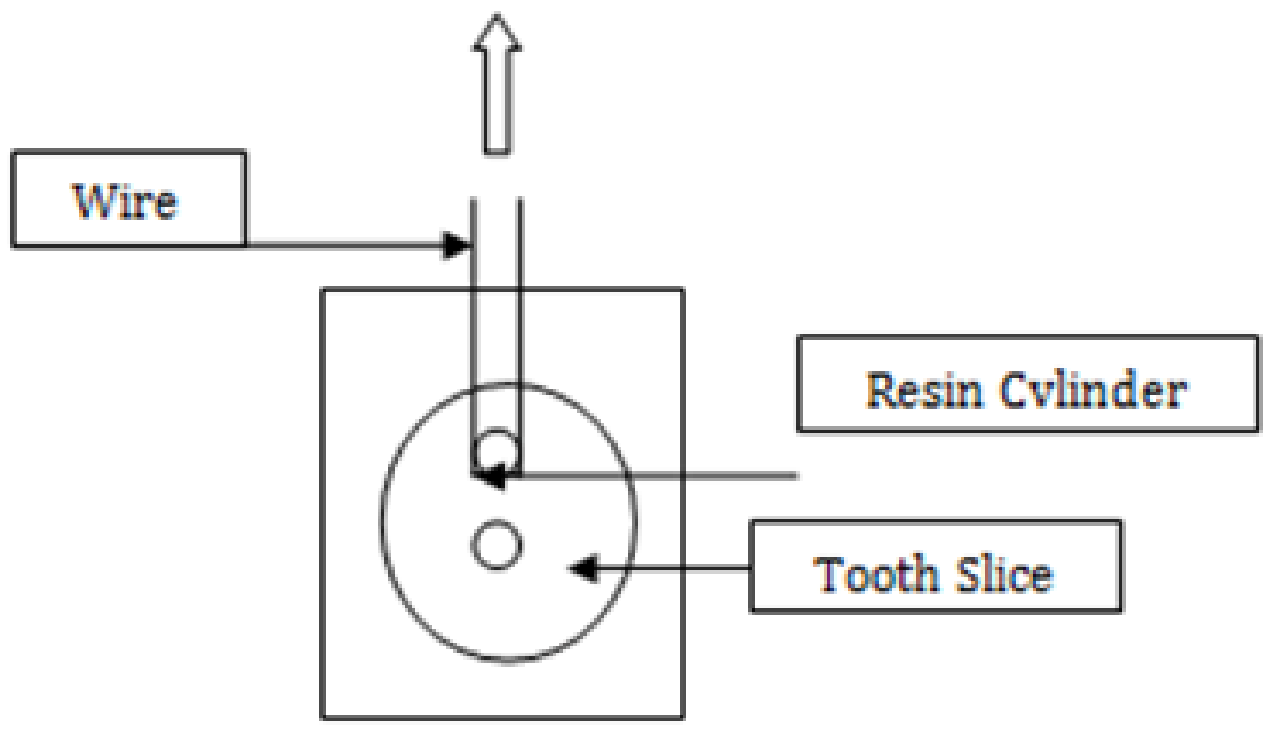

Figure I Diagram showing the micro-shear bond test setup. 


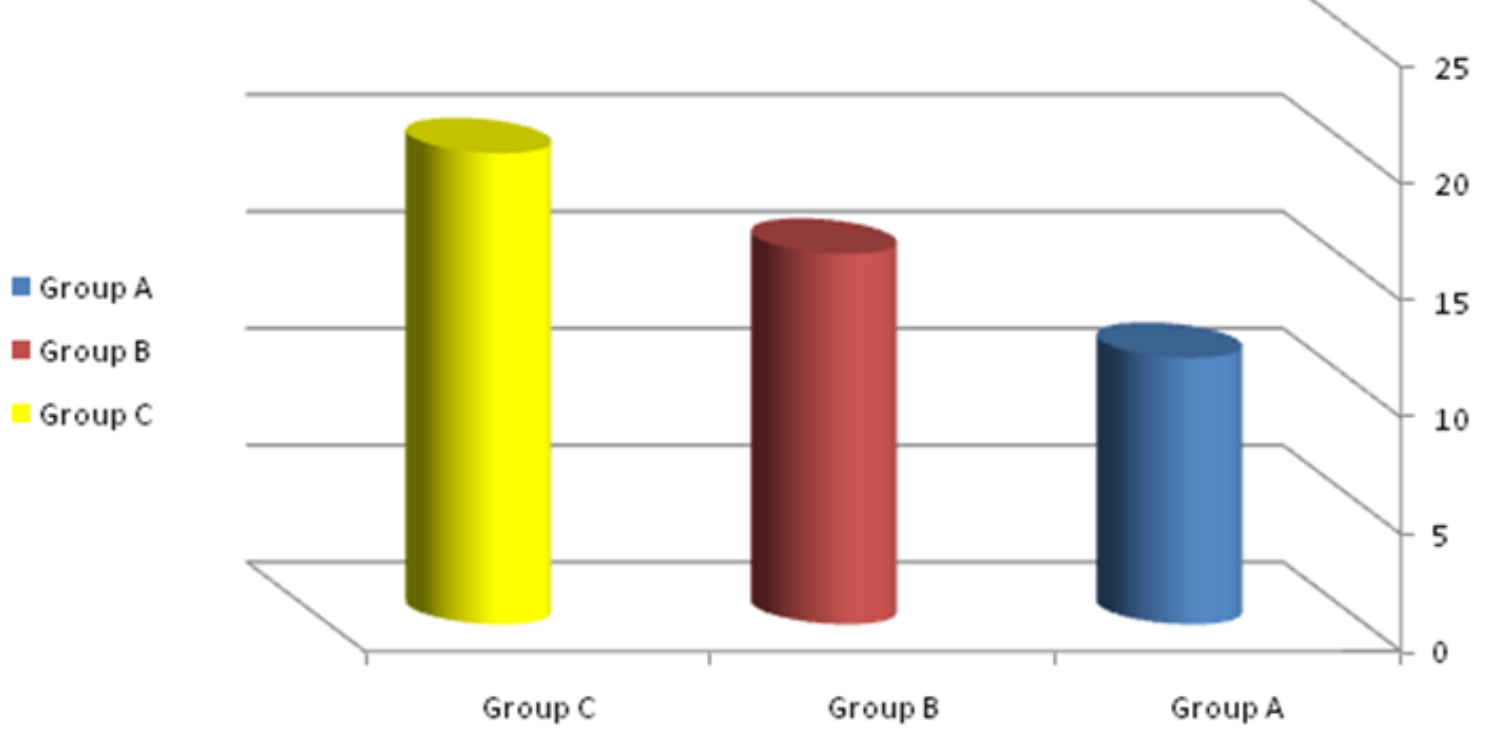

Figure 2 Bar chart showing means micro-shear bond strength in (MPa) of the tested groups.

\section{Results}

The mean micro-shear bond strength values (Mpa), standard deviations, and statistical results of the materials are given in (Table 1). Micro-shear bond strength values for Sonic Fill Bulk fill composite group C (17.16 Mpa) was significantly greater than Tetric Evo Ceram Bulk fill (group B (13.85 Mpa) and nano-filled Composite group A (10.4 Mpa). There were significant differences between nanofilled Composite, Tetric EvoCeram Bulk fill and Sonic Fill Bulk fill composite $(\mathrm{P}<0.05)$.

Table I Comparison between micro-shear bond strength ( $\mathrm{MPa})$ of the tested groups

\begin{tabular}{|c|c|c|c|c|c|c|}
\hline \multicolumn{2}{|c|}{ Group A } & \multicolumn{2}{|c|}{ Group B } & \multicolumn{2}{|c|}{ Group C } & \multirow{3}{*}{ P-value } \\
\hline \multicolumn{2}{|c|}{ Nanofilled composite and } & \multicolumn{2}{|c|}{ Tetric evo ceram bulk fill } & \multicolumn{2}{|c|}{ Sonic fill bulk fill composite } & \\
\hline Mean & SD & Mean & SD & Mean & SD & \\
\hline $10.4 \mathrm{a}$ & 0.8 & $13.85 \mathrm{~b}$ & 1.2 & $17.16 \mathrm{c}$ & I.I & $<0.00 I^{*}$ \\
\hline
\end{tabular}

\section{Discussion}

Simplified and fast restorative procedures, such as placing resin composite in bulk instead of layering or the use of simplified single component self-etching adhesives instead of multistep self-etching or etch-and-rinse systems are becoming more and more popular. The efficiency of such simplified restorative procedures and their long-lasting clinical effects are however controversially discussed. The present study measured the micro-shear bond strength of three different composites bonded with a nano adhesive. In-vitro mechanical test are of utmost importance to evaluate and compare bond strengths of adhesive systems to enamel and dentin. The most commonly employed test setup for this purpose is tensile and shears tests. ${ }^{29}$ Shear bond strength tests have been widely used, mainly because of their relative simplicity and predictability when compared to tensile bond strength tests, in which it is difficult to align the specimen in the testing machine without creating deleterious stress distribution. ${ }^{30}$ Advantages in shear tests include specimen preparation and simple test protocols. ${ }^{31}$ A new test method using specimens with reduced dimensions has been advocated by some authors ${ }^{32,33}$ as a substitute for the conventional shear test: so-called microbond or micro-shear bond strength test. According to them, this test allows for testing of small areas, thus permitting a regional mapping or depth profiling of different substrates and preparing multiple specimens from the same tooth. In this study, we used Nano bond adhesive with Sonic Fill Bulk Fill composite, nanofilled Composite and Tetric EvoCeram Bulk fill. Nano Bond is nano particulate reinforced adhesive system. The NanoBond resin is reinforced with a unique, functional, nano-particle (see below for details) that strengthens the resin while it infiltrates the etched surface and provides a strong interface. The Nano-Bond system contains polyhedral-shaped, surface functional nano-particles. This new technology bridges the property space between hydrocarbonbased plastics and ceramics. These structures are characterized by their 3 dimensional, "cage-like" molecular shapes, which increases modulus and hardness while maintaining the stress and strain characteristics of the base resin. This advanced nono reinforced resin was chosen to be used for all composites in this comparative study.

The results of this study showed that nano bond with Sonic Fill composite displayed the highest micro-shear bond strength(17.16MPa) in comparison to nano composite (10.4MPa) and Tetric EvoCeram Bulk fill (13.85MPa) and all three composites, when compared for micro-shear had a significant difference $(\mathrm{P}<0.001)$. The results may be attributed to Bulk Fill composites having higher filler content and thus improved mechanical properties. The composite contains about $83.5 \%$ of fillers by weight, mainly silica and barium aluminoborosilicate glass. Due to an enhanced translucency and by incorporating a photoactive group in the methacrylate resin, 
polymerization kinetics are claimed to be better controlled. ${ }^{34}$ Additionally, oscillation energy temporarily increases flowability of Sonic Fill to achieve precise interaction with the bonding agent and the rapid placement through a single increment up to $5 \mathrm{~mm}$ leading to reduced polymerization shrinkage, thereby reducing working time and increased mechanical strength. ${ }^{35}$ The ultra-sonic activation in Sonic Fill resin with special modifiers that react to sonic energy cause the viscosity to drop (up to $87 \%$ ), increasing the flowability of the composite enabling quick placement and precise adaptation. When the sonic energy is stopped, the composite returns to a more viscous, no slumping state that is perfect for carving and contouring. ${ }^{3.5}$ In case of the other two composites, this activation is missing. Tetric Evo Ceram has increased depth of cure due to presence of Ivocerin, a germanium based initiator system with higher photocuring depth to preparation walls and to bonding agent interface. The filler loading is 87 percent making it too viscous to adapt properly despite having good curing depth. ${ }^{34,35}$ The Artiste Nano-composite has filler loading of 66 percent by volume which is less than the other two composites. Resin composites exhibit viscoelastic behavior and are transformed during polymerization from a viscous plastic to a rigid elastic structure. The polymerization shrinkage of the matrix, combined with a limited adhesion force of adhesive systems to dental tissue, challenges the stability of a restoration. In addition, adhesive bonding of composites to teeth results in contraction stresses, the magnitude of which is dependent upon several factors. Thus, the development of contraction stress in dental composites depends upon the material composition, including the type of monomer; the type and amount of filler; filler/ matrix interactions; polymerization parameters such as the degree and rate of polymerization, placement and curing technique. In this study, the ultrasonic placement activation along with the high filler content played a major role in enhanced bonding to dentin

\section{Conclusion}

Sonic Fill Bulk fill composite and nano bond adhesive displayed highest micro-shear bond strength in comparison with nano-composite and Tetric EvoCeram Bulk fill composite. Due to the ability to place restorations in single increments and ease of use, the sonic fill composite can be a viable alternative for posterior restorations.

\section{Funding}

None.

\section{Acknowledgments}

None.

\section{Conflicts of interest}

Authors declare that there is no conflict of interest.

\section{References}

1. Frost P. An audit on the placement and replacement of restorations in a general dental practice. Primary Dental Care. 2002;9(1):31-36.

2. Bayne S, Thompson J, Swift E, et al. A characterization of first-generation flowable composites. J Am Dent Assoc. 1998;129(5):567-577.

3. Lim B, Ferracane J, Sakaguchi R, et al. Reduction of polymerization contraction stress for dental composites by two-step light-activation. $J$ Dent Mater. 2002;18(6):436-444.

4. Watts D, Marouf A, Hindi A. Photo-polymerization shrinkage-stress kinetics in resin-composites: methods development. J Dent Mater. 2003;19(1):1-11
5. $\mathrm{Xu} \mathrm{X}$, Ling $\mathrm{L}$, Wang $\mathrm{R}$, et al. Formation and characterization of a novel fluoride-releasing dental composite. $J$ Dent Mater. 2006;22(11):1014-1023.

6. Drummond J. Degradation, fatigue, and failure of resin dental composite materials. J Dent Res. 2008;87(8):710-719.

7. Samuel S, Li S, Mukherjee I, et al. Mechanical properties of experimental dental composites containing a combination of mesoporous and nonporous spherical silica as fillers. J Dent Mater. 2011;25(3):296-301.

8. Ferracane J. Resin composite state of the art. J Dent Mater. 2011;27(1):29-38.

9. Imazato S, Torii M, Tsuchitani Y, et al. Incorporation of bacterial inhibitor into resin composite. J Dent Res. 1994;73(8):1437-1443.

10. Zalkind M, Keisar O, Ever Hadani P, et al. Accumulation of Streptococcus mutans on light-cured composites and amalgam: an in vitro study. $J$ Esth Dent. 1998;10(4):187-190.

11. Beyth N, Domb A, Weiss E. An in vitro quantitative antibacterial analysis of amalgam and composite resins. J Dent. 2007;35(3):201-206.

12. Jokstad A, Bayne S, Blunck U, et al. Quality of dental restorations. FDI Commission Projects 2-95. Int Dent J. 2001;51(3):117-158.

13. Sakaguchi R. Review of the current status and challenges for dental posterior restorative composites: clinical, chemistry, and physical behavior considerations. J Dent Mater. 2005;21(1):3-6.

14. Davidson C, Feilzer A. Polymerization shrinkage and polymerization shrinkage stress in polymer-based restoratives. $J$ Dent. 1997;25(6):435-440.

15. Braga R, Hilton T, Ferracane J. Contraction stress of flowable composite materials and their efficacy as stress-relieving layers. $J$ Am Dent Assoc. 2003;134(6):721-728.

16. Roggendorf M, Kramer N, Appelt A, et al. Marginal quality of flowable 4-mm base vs. conventionally layered resin composite. J Dent. 2011;39(10):643-647.

17. Garcia Godoy F, Kramer N, Feilzer A, et al. Long-term degradation of enamel and dentin bonds: 6-year results in vitro vs. in vivo. Dental Materials. 2010;26(11):1113-1118.

18. Versluis A, Douglas WH, Cross M, et al. Does an incremental filling technique reduce polymerization shrinkage stresses? J Dent Res. 1996;75(3):871-888.

19. Ying Z, Li X, Chen B, et al. Highly exfoliated epoxy/clay nanocomposites: Mechanism of exfoliation and thermal/mechanical properties. Comp Stru. 2015;132:44-49.

20. Manne U, Sunil K, Arvind K, et al. Comparing marginal microleakage of three Bulk Fill composites in Class II cavities using confocal microscope: An in vitro study. J Conserv Dent. 2015;18(5):409-413.

21. Giachetti L. A new method for direct composite restoration of the posterior teeth. J Dental Tribune Middle East and African edition; 2014.

22. MC Donough W, Antonucci J, He J, et al. A micro-shear test to measure bond strengths of dentin-polymer interfaces. Biomater. 2002;23(17):3603-3608.

23. McDonough W, Antonucci J, Dunkers J. Interfacial shear strengths of dental resin-glass fibers by the microbond test. Dent Mater. 2001;17(6):492-498.

24. Shimada Y, Iwamoto N, Kawashima M, et al. Shear bond strength of current adhesive systems to enamel, dentin and dentin-enamel junction region. Oper Dent. 2003;28(5):585-590.

25. Shimada Y, Kikushima D, Tagami J. Micro-shear bond strength of resin bonding systems to cervical enamel. Am J Dent. 2003;15(6):373-377. 
26. American Dental Association (ADA) Council on Scientific Affairs: American National Standards Institute/American Dental Association (ANSI/ADA) No. 27: Dentistry-polymer-based filling restoration and lating material 263-267; 2002.

27. Mechanical specification 11405; Dental materials, testing of adhesion to tooth structure. International Organization for Standardization (ISO); 2001.

28. Janda R, Roulet S, Latta M, et al. The effects of thermocycling on the flexural strength and flexural modulus of modern resin-based filling materials. J Dent Res. 2006;22:812-817.

29. Tantbirojn D, Cheng Y, Versluis A, et al. Nominal shear or fracture mechanics in the assessment of composite-dentin adhesion. J Dent Res. 2000;79(1):41-48.

30. Sudsangiam S, Van Noort R. Do dentin bond strength tests serve a useful purpose? J Adhes Dent. 1999;1(1):57-67.
31. McDonough W, Antonucci J, $\mathrm{He} \mathrm{J}$, et al. A micro-shear test to measure bond strengths of dentin-polymer interfaces. Biomaterials. 2002;23(17):3603-3608.

32. Shimada Y, Kikushima D, Tagami J. Micro-shear bond strength of resin bonding systems to cervical enamel. Am J Dent. 2003;15(6):373-377.

33. Toba S, Veerapravati W, Shimada Y, et al. Micro-shear bond strength of adhesive resins to coronal dentin versus the floor of the pulp chamber. $\mathrm{Am}$ Dent J. 2003;16:51-56.

34. Van Ende A, De Munck J, Van Landuyt KL, et al. Bulk-filling of high C-factor posterior cavities: Effect onadhesion to cavity-bottom dentin. Dent Mater. 2013;29(3):269-277.

35. Eunice C, Margarida A, João C, et al. $99 \mathrm{mTc}$ in the evaluation of microleakage of composite resin restorations with SonicFillTM. An in vitro experimental model. Open J Stomatol. 1999;2(4):340-347. 